\title{
Effects of stress on health and aging: Two paradoxes
}

by Carolyn M. Aldwin and Loriena A. Yancura

\begin{abstract}
Although older adults are thought to experience more stress and to be
\end{abstract} more vulnerable to its adverse effects, they often report less stress than younger adults and sometimes show more resilience. Paradoxically, while stress sometimes has long-term positive effects on well-being, studies differ as to whether this increases or decreases with age. We conclude that older individuals have learned to appraise and cope differently with stress. This protects them in spite of their increased physiological vulnerability and may also increase the possibility of stress-related growth and optimal aging.

$\mathrm{O}$ ver the past century, remarkable changes have occurred in the life expectancy and quality of life of older adults. Individuals born in the United States in 1900 had an average life expectancy of 47.3 years; those born in 2004 are expected to live 77.8 years on average (NCHS 2006). Life expectancy projections for residents of California are even higher than national estimates: individuals born in 2004 are expected to live 80.2 years (Springborn 2006).

These increases do not come without costs; they are accompanied by corresponding increases in both the incidence (new cases) and prevalence (current cases) of chronic health conditions, most commonly cardiovascular disease, arthritis, diabetes and cancer. These chronic health problems may greatly influence older adults' wellbeing and productivity, as disability rates increase dramatically after age 65 . One quarter (25.5\%) of U.S. adults over age 65 report that their daily activities are limited by one or more chronic health condition, but $43.9 \%$ of those over age 75 report similar limitations (NCHS 2006). However, many older adults are in good or excellent health

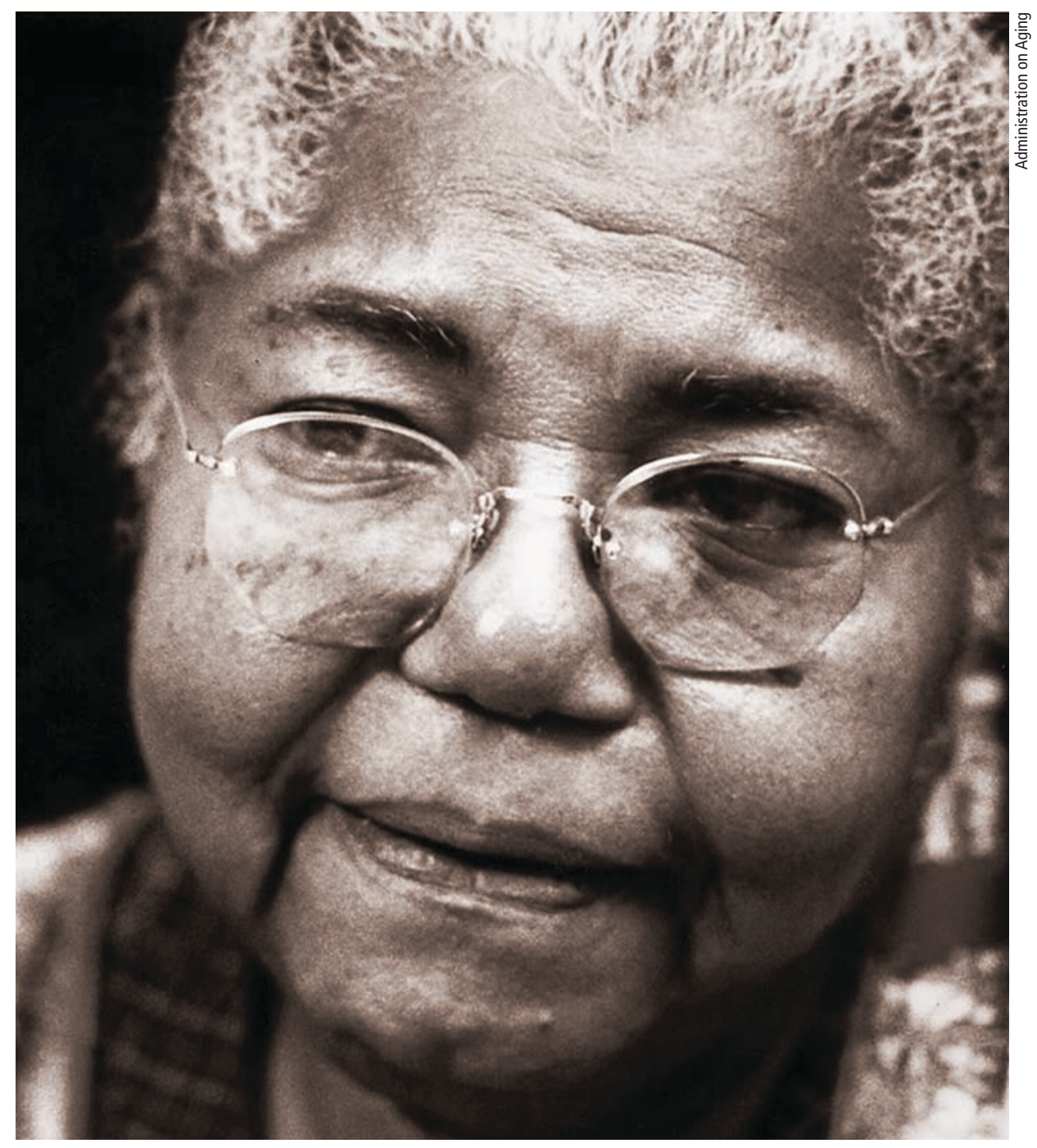

As people age their health trajectories tend to diverge, with some developing multiple chronic conditions and others maintaining good health; stress may play a role in this aspect of aging.

(Rowe and Kahn 1998). In California, older adults are often actively engaged in farming, golfing, skiing - and even running marathons.

Individual health differences increase with age, and these differences are thought to be greater in late life than any other phase of the life span. Over time, people have increasingly different patterns of health trajectories. Aldwin et al. (2001) examined patterns of change, then clustered or grouped individuals by both intercept (baseline level) and the shape of the curve. Those in Cluster 1 began with the lowest symptom levels, which increased only slowly with age (fig. 1). Individuals in this cluster can be thought of as optimally aging. In contrast, people in Cluster 0 started out with the highest symptom levels, which increased rapidly, while other people showed various nonlinear patterns. Another study using this sample suggested that individuals - in this case combat veterans who had also experienced subsequent civilian traumas like serious car accidents - had rapid increases in physical symptoms (Schnurr et al. 1998). This sparked our interest in the effects of stress on the aging process.

\section{Effects of stress on health}

Until the 1970s, medical researchers were skeptical about the effects of stress on health. With thousands of 
studies conducted, the impacts of stress and physiological processes are now widely recognized, although showing that specific illnesses stem from stress is somewhat difficult (Aldwin 2007). Not only our minds but also our bodies respond to stressors, which may be physical (such as temperature) or psychosocial (such as a trauma, life event, daily stressor or chronic stressor).

The stress response begins when the individual appraises a situation as involving a threat, harm/loss or challenge (Lazarus and Folkman 1984). The appraisal and its attendant negative emotions activate the sympathetic nervous system to bring more energy to the body for a fight/flight response. The immediate reaction is that the sympathetic neurons release catecholamines (adrenaline and noradrenaline) directly to the heart and other organs. This increases the heart rate, blood pressure and respiratory rate so the individual can run faster or think more clearly. This reaction can be sustained by the sympathetic-adrenal-medullary (SAM) system, which is also involved in the release of catecholamines from the adrenal medulla, or center of the adrenal gland (fig. 2).

Adrenaline in large amounts can be toxic, so for sustained stress responses, the hypothalamic-pituitary-adrenal (HPA) axis becomes activated (fig. 2). Cortisol and other glucocorticoids are released from the adrenal cortex, which mobilize resources to sustain action. These include changes in metabolism (increased blood glucose and lipid

\section{Glossary}

Chronic stressors: Enduring problems, especially in social roles, such as living in poverty or caring for a seriously ill family member.

Daily stressors: Problems of everyday life such as commuting or minor arguments with a spouse.

Life events: Major changes such as divorce or being laid off from work.

Trauma: Stressors that involve mortal threats such as combat or natural disasters.

levels), the cardiovascular system (increased heart rate and blood pressure) and the immune system (changes in circulating T cells, B cells and lymphocytes). In the short term, these resources are useful in helping the body deal with stressors. For example, increases in blood glucose levels provide more fuel for the muscles and brain, and increases in certain immune cells can facilitate blood clotting in response to an injury. In the long run, however, elevated blood glucose and lipids (cholesterol) in the blood can lead to chronic illnesses such as diabetes and cardiovascular disease, and the immune system can become suppressed. This is why chronic stress may contribute more to the development of chronic illnesses than life events per se (Friedman and McEwen 2004).
A wide range of stressors can evoke physiological responses. We know that stress induced by public speaking results in increased cortisol levels (Feldman et al. 2004), and driving buses in urban settings increases catecholamine levels (Evans and Carrère 1991). We also know that family caregivers for people with Alzheimer's disease appear to have less-efficient immune profiles than those who are not experiencing chronic caregiving stress (KiecoltGlaser et al. 2002). While these findings provide evidence that stress influences parameters in several physiological systems, they do not necessarily prove that stress causes discrete illnesses.

\section{The progression of illnesses}

A recent review of the literature on psychological stress and disease (Cohen et al. 2007) concluded that there is considerable support for a link between stress and certain illnesses such as depression, cardiovascular disease and the progression of AIDS. There is also growing evidence for the role of stress in the incidence and progression of other diseases such as upper respiratory tract infections, asthma, autoimmune diseases and delayed wound healing. Research using animals provides strong evidence for a link between stress and cancer, but in humans this link is much weaker.

In humans, stress may have more influence on the progression, rather than the occurrence, of these diseases. For example, a woman who has experienced a great deal of chronic stress

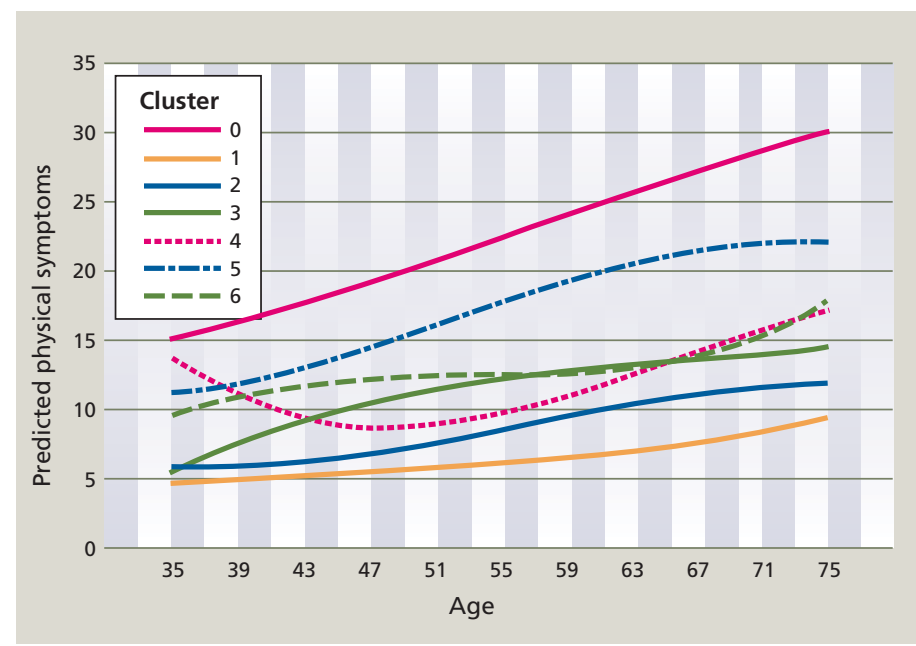

Fig. 1. Patterns of individual differences in symptom change over time. Source: Aldwin et al. 2001.

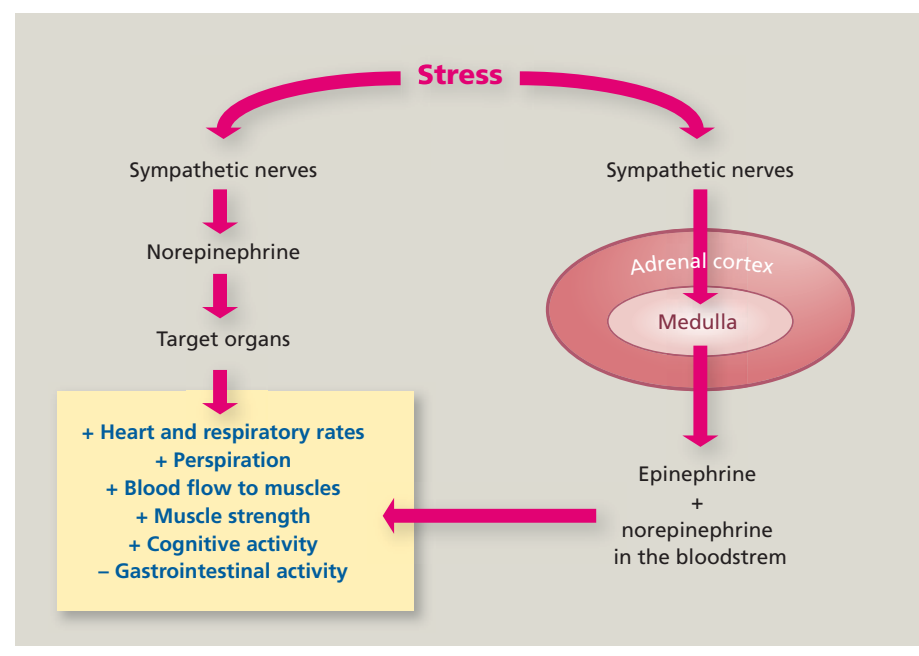

Fig. 2. Two pathways in the stress activation of the sympathetic nervous system. Source: Aldwin et al. 2007a. 


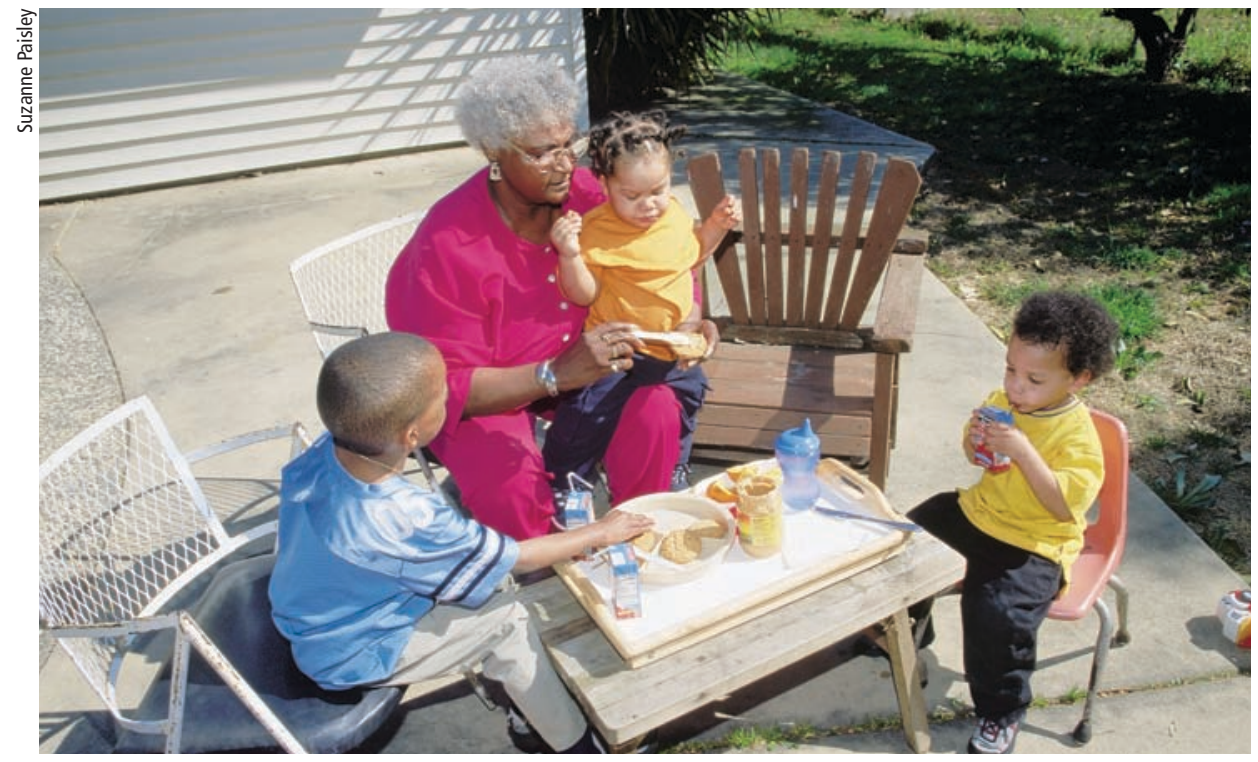

Adults often face multiple challenges as they age - such as providing full-time care for grandchildren - but on the whole they report less stress than younger adults.

might have the same odds of getting breast cancer as a woman who has not. However, if both women get cancer, it might progress more quickly in the one with the high level of chronic stress.

Despite the indisputable fact that stress has adverse effects on health, it is by no means assured that stressed individuals will always get sick, or that sickness will come only to individuals who are stressed. Indeed, the correlations in naturalistic field studies are modest for self-reported health outcomes, and weaker even than that for biomedical outcomes such as elevated cholesterol levels (Aldwin 2007). Nonetheless, stress may play a role in the different trajectories of health across the life span, and may partially account for the increase in individual health differences in later life (age 65 and older).

\section{Stress paradoxes}

Our laboratory has carried out studies of two major stress paradoxes. The first paradox concerns some surprising findings about the relationship between age and stress - that older adults report less stress, often despite poorer objective circumstances such as chronic illness, bereavement and reduced income. Further, there is disagreement in the research literature as to whether older adults are more or less vulnerable to psychosocial stressors than younger adults. The second paradox addresses the positive aspects of stress - that, under certain conditions, stress can have positive, or toughening, effects on physical health (Dienstbier 1989).

We have been investigating these paradoxes in two major longitudinal studies, the Normative Aging Study (NAS) and the Davis Longitudinal Study (DLS). The original sample in the NAS was 2,280 men aged 22 to 80 , mostly veterans, who were screened for good health in the mid-1960s. They have been followed ever since through a series of biomedical examinations, surveys and interviews that include measures of personality, stress, coping strategies and other factors.

The DLS is composed of UC Davis alumni from the classes of 1967 to 1969, 1979, 1989 and 1999, split roughly equally between men and women. Started by Professor Mary Reagan in the mid-1960s, the study's original focus was the impact of education on value systems. By 1990, though, the focus had shifted to stress and health. Funded largely through Hatch funds from the Agricultural Experiment Station, DLS participants responded to surveys of stress, coping and health in 1990, 1996 and 2001.

\section{Older people and life events}

For decades it was a truism that stress increased in later life. After all, older people are more likely to develop chronic illnesses, become widowed, lose friends and loved ones, experience decreased status and income with retirement, and live alone. But an early review of the literature showed that older adults report fewer life events than do young adults (Rabkin and Streuning 1976). If older adults face so many challenges in their lives, why do they report less stress?

Early life-event scales focused on events that mainly affect young people, such as graduation, marriage, divorce or being jailed. As a postdoctoral scholar at UC Irvine, the first author lived briefly in a large retirement community and spent much of her time simply observing and chatting with individuals, which yielded a glimpse of the problems that older adults were facing. This informal research was the basis for the Elders Life Stress Inventory (ELSI), which included more of the types of events faced by middle-aged and older adults. These included deaths of family members and friends as well as "network stressors" such as their child's divorce or indebtedness. Preliminary studies found few age differences in the number of stressful life events between middle-aged men and older men in the NAS on the ELSI (Aldwin 1990), although subsequent research suggested a slightly nonlinear relationship, with the number of life events increasing until about 65 and decreasing thereafter (Yancura et al. 1999).

Nonetheless, studies using the DLS data showed that there are age differences in the types of problems reported as "low points" by young versus

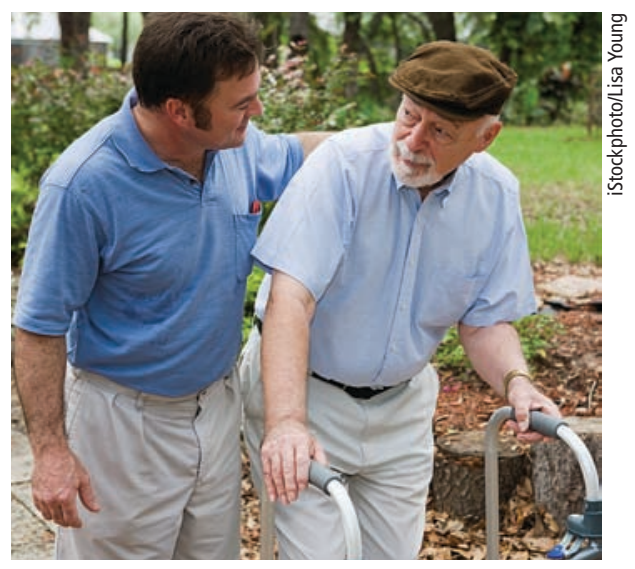

In standardized stress inventories, middle-aged adults reported family issues such as their parents' health as stressors, while older adults reported that their own health problems and "daily hassles" were stressful. 
middle-aged adults (Shiraishi and Aldwin 2002). Middle-aged adults were more likely to list family problems, parents' health and other health problems, reflecting their position as the "sandwich" generation, while young adults were coping with work problems and "angst," a general category that included problems with one's identity or mental health. The number of major problems does not seem to decrease much, if at all, with age, but the types of problems may change, as stressors are often linked to our social roles. Young adults struggle to establish their own careers, while in middle adulthood and late life, individuals often have more generative concerns about taking care of their families and older relatives.

The increase in social responsibilities, however, does not seem to lead to an increase in hassles, or daily stressors. In the NAS, older adults reported fewer daily stressors (Aldwin, Sutton, Chiara, et al. 1996). Not surprisingly, the types of problems reported also varied by age: middle-aged men reported more daily stressors with work and family life, while older adults reported more problems with health and "daily hassles," a category that included activities such as home maintenance and volunteering. Despite extensive questioning, nearly $20 \%$ of individuals 80 and older could not come up with a single problem in the past week.

\section{Dealing with problems}

Given that older adults have more health difficulties and losses, why don't they report more problems? The answer seems to be in how they appraise problems. Older adults are less likely to perceive their problems as stressful. This does not seem to be due either to personality changes with age, or to the types of problems they face. Rather, we

\section{Older adults are less likely to perceive their problems as stressful.}

believe that older adults' greater experience with many types of problems gives them a more balanced perspective on their daily stressors (Boeninger et al. 2009).

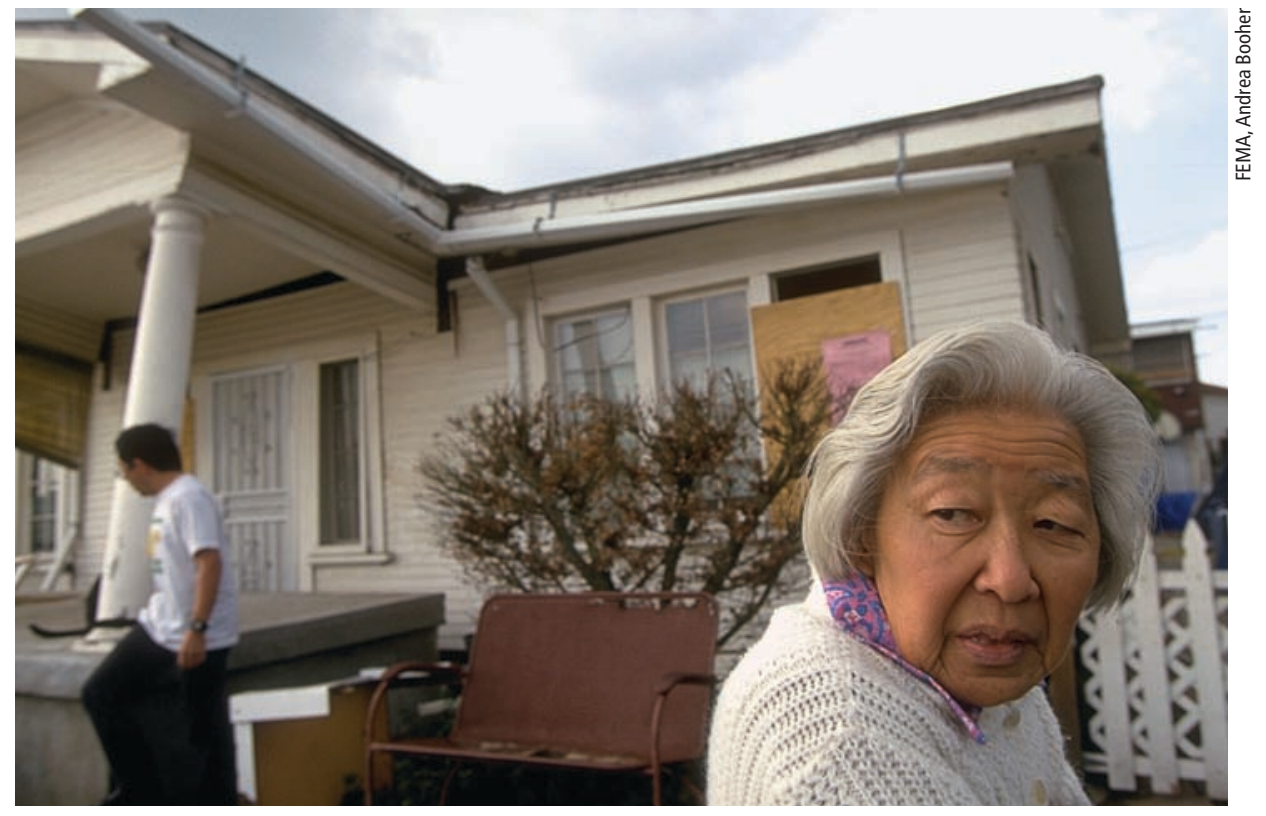

Some studies have shown that older adults are more resilient and less susceptible to the psychological impacts of stressful life events. Above, a senior was displaced by a Southern California earthquake.

How vulnerability to stress changes with age is more complex. We know that both infants and older adults are more vulnerable to physical stressors, such as temperature extremes or massive population dislocations. These two groups are more likely to contract influenza or die in refugee camps. Neither group regulates body temperature well, so they are more likely to die of heat stroke. For example, thousands of older adults died during heat waves in Chicago and Europe a few years ago.

However, there is a controversy over whether the health of older adults is more or less vulnerable to psychosocial stressors than that of younger adults. While many assume that older adults are more vulnerable due to impaired immune function and chronic illnesses, some studies have found that those who survive into late life may be fairly resilient and less vulnerable to stress. For example, we have known for many years that older adults who are widowed have higher mortality rates in the following year. However, Johnson et al. (2000) found that middleaged adults who lost their spouses had higher mortality rates than bereaved older adults.

In part, this may be due to survivor effects. For example, people in higher socioeconomic status groups have lower mortality rates than poorer individuals with less education and thus are less likely to survive to late life (Marmot et al. 1991). Also, personality affects mortality: individuals who have a high degree of hostility are more likely to die in midlife (Krantz and McCeney 2002).

There may also be age differences in the types of illnesses that stress affects. Preliminary research from our laboratory suggests that chronic stress in young adulthood results in acute illnesses such as headaches, backaches and colds, while chronic stress in midlife results in chronic illnesses (and their risk factors) such as hypertension or high cholesterol (Aldwin et al. 2002).

In 2003, we received funding from the UC Davis College of Agriculture and Environmental Sciences, as well as the American Psychological Association, to hold a conference where researchers from a variety of disciplines were asked to specifically examine this question. The immediate answer resulting from the conference was, "We don't really know," because studies either had not yet been done or yielded contradictory results. Nonetheless, the resulting publication pulled together enough information to support an intriguing hypothesis (Aldwin et al. 2007a). We think that older adults actually may be physiologically more vulnerable to both physical and psychosocial stressors. 
Even in healthy older adults, the neuroendocrine and immune systems often show slower returns to normal after stress activation, but some studies found that older adults have lower stress responses.

We hypothesize that this is because, knowing their greater vulnerability, older adults consciously avoid becoming upset by minor problems to prevent increases in health problems (Aldwin et al. 2007b). For example, one older man in one of our NAS studies remarked that he used to get upset about little things, but now that he has high blood pressure, he can't afford to anymore (Aldwin, Sutton, Chiara, et al. 1996). Older adults may be less likely to appraise situations as problematic (Boeninger et al. 2009), which might account for both their lower levels of reported stress and sometimes better physical profiles under stress.

\section{Positive aspects of stress}

The second paradox concerns the positive aspect of stress, sometimes called "post-traumatic growth" (Tedeschi and Calhoun 2004) or "stressrelated growth" (Park and Fenster 2004). Although we know that stress has adverse effects on health, even individuals undergoing extreme stress can point to the "silver lining" in their experiences. Negative experiences like divorce, war or job loss can often become "turning points" for positive change.

These individuals often point to increases in mastery and coping skills, more positive values, closer relationships with loved ones, and sometimes, increased spirituality. A study using data from the DLS found that only about $10 \%$ of individuals reported exclusively negative long-term outcomes of low points in their lives, while $20 \%$ reported exclusively positive long-term outcomes. Only about $10 \%$ said there were no long-term effects, while most (60\%) reported mixed outcomes, that is, there were both positive and negative longterm consequences (Aldwin, Sutton, Lachman 1996).

In this study, we also examined factors that were associated with the long-term outcomes of low points. The type of problem did not seem to matter, for example, whether it was related to family or work; rather, how individuals coped was of greatest importance. The use of positive coping strategies such as problem-focused coping - defined as cognitive and behavioral attempts to solve or manage the problem, taking perspective and self-regulation allowed individuals to benefit from stressful experiences, while negative coping strategies such as blaming others, escapism and the use of drugs or alcohol to regulate emotions were associated with poorer outcomes (Aldwin, Sutton, Lachman 1996).

A critical issue in the field of stressrelated growth is whether older individuals are more or less likely to find benefits in problems. The literature is mixed, with many studies showing no age effects, some showing that younger adults are more likely to report stressrelated growth, and a few studies showing that older adults are more likely to do so (Stanton et al. 2006).

In a DLS follow-up study, we examined the effects of age on stress-related growth, and found two contradictory paths (Aldwin et al. 2009). First, age was negatively correlated with stress-related growth, suggesting that younger adults were more likely to perceive the positive aspects of stress. In many ways, this makes sense, because we encourage our young people to "learn from their mistakes," and not let (presumably temporary) setbacks discourage them. However, the middle-aged adults were more likely to use positive coping strategies, which in turn was positively associated with stress-related growth. There may be individual differences in perceiving benefits. If individuals learn to derive positive benefits even from low points in their lives. This ability may become enhanced with age.

However, why was there still a negative correlation between age and stressrelated growth? Recently, we examined two other stressor characteristics - the severity of the problem and its duration (Bi et al. 2008). The more stressful the problem, the more likely people were to report stress-related growth. Yet, there was no relationship between stress severity and age. The duration of the low point was positively associated with stress-related growth, but middle-aged individuals were more likely experience chronic stressors such as caregiving for loved ones or chronic illnesses. It is therefore unclear why there is a negative correlation with age.

\section{Optimal aging}

California and most of the rest of the world will experience a massive 
increase in the number of older adults in the next three decades. It is imperative that we understand what promotes optimal aging in order to maintain seniors in good health as long as possible, protect their quality of life and decrease the economic burdens on society. Understanding how to protect individuals from the negative effects of stress is one way of doing this.

Stress is ubiquitous - we all will experience problems at various points in our lives. The process of finding benefits in even the worst of problems may be protective of psychological health and perhaps physical health. Further, it is likely that the two paradoxes discussed here are linked. Positively coping with stress as a young or middle-aged adult may well provide a better perspective on one's problems, and life in general. This enhanced perspective may become protective in later life. Older adults who are successfully aging may have learned how to avoid becoming upset over relatively minor problems - or even chronic ones thereby decreasing their negative responses to stress, protecting their health and promoting optimal aging.

\section{C.M. Aldwin is Professor, Department of Hu-} man Development and Family Sciences, Oregon State University; and L.A. Yancura is Associate Professor, Department of Family and Consumer Sciences, University of Hawai'i, Manoa. Data collection on the DLS study was supported by Hatch funds from the Agricultural Experiment Station.

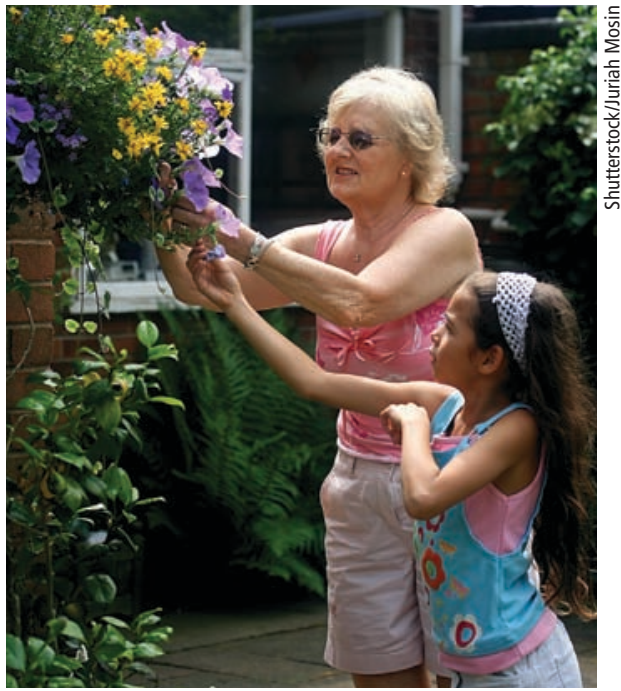

While stress is ubiquitous in life, older adults who have learned how to manage it may age the most gracefully and healthfully.

\section{References}

Aldwin CM. 1990. The Elders Life Stress Inventory (ELSI): Egocentric and nonegocentric stress. In: Stephens MAP, Hobfoll SE, Crowther JH, Tennenbaum DL (eds.). Stress and Coping in Late Life Families. New York, NY: Hemisphere. p 49-69

Aldwin CM. 2007. Stress, Coping and Development: An Integrative Approach (2nd ed.). New York, NY Guilford. $432 \mathrm{p}$.

Aldwin CM, Levenson MR, Kelly LL. 2009. Life span developmental perspectives on stress-related growth. In: Park CL, Lechner S, Stanton A, Antoni M (eds.). Positive Life Changes in the Context of Medical IIIness. Washington, DC: APA Pr. p 87-104.

Aldwin CM, Park CL, Spiro A III. (eds.). 2007a. Handbook of the Health Psychology and Aging. New York NY: Guilford. 450 p.

Aldwin CM, Park CL, Spiro A III. 2007b. Health psychology and aging: Moving to the next generation of research. In: Aldwin CM, Park CL, Spiro A III (eds.). Handbook of Health Psychology and Aging. New York NY: Guilford. p 413-26.

Aldwin CM, Shiraishi RW, Levenson MR. 2002. Is health in midlife more vulnerable to stress? Paper presented at Annual Meetings of the American Psychological Association, Chicago, IL.

Aldwin CM, Spiro A III, Levenson MR, Cupertino AP. 2001. Longitudinal findings from the Normative Aging Study. III. Personality, individual health trajectories and mortality. Psychol Aging 16:450-65

Aldwin CM, Sutton KJ, Chiara G, Spiro A III. 1996. Age differences in stress, coping and appraisal: Findings from the Normative Aging Study. J Gerontol: Psych Sci 51B:179-88.

Aldwin CM, Sutton K, Lachman M. 1996. The development of coping resources in adulthood. J Personality 64:91-113.

Bi X, Taylor A, Aldwin CM. 2008. Age and stressrelated growth: Findings from the Davis Longitudinal Study. Paper presented at American Psychological Association, Boston, MA.
Boeninger DK, Shiraishi RW, Aldwin CM, Spiro A III. 2009. Why do older men report lower stress ratings? Findings from the Normative Aging Study. Int J Aging Hum Dev 68(2):149-70.

Cohen S, Janicki-Deverts D, Miller GE. 2007. Psychological stress and disease. J Am Psychol Assoc 298:1685-7

Dienstbier RA. 1989. Arousal and physiological toughness: Implications for mental and physical health. Psychol Rev 96:84-100.

Evans GW, Carrère S. 1991. Traffic congestion, perceived control and psychophysiological stress among urban bus drivers. J Appl Psychol 76(5):658-63.

Feldman PJ, Cohen S, Hamrick N, Lepore SJ. 2004 Psychological stress, appraisal, emotion and cardiovascular response in a public speaking task. Psycho Health 19(3):353-68.

Friedman MJ, McEwen BA. 2004. Post-traumatic stress disorder, allostatic load and medical illness. In: Schnurr PP, Green BL (eds.). Trauma and Health: Physical Health Consequences of Exposure to Extreme Stress. Washington, DC: Am Psychol Assoc. p 157-88.

Johnson JV, Backlund E, Sorlie PD, Loveless CA. 2000 Marital status and mortality: The National Longitudinal Mortality Study. An Epidemiol 10:224-38.

Kiecolt-Glaser JK, McGuire L, Robles TF, Glaser R. 2002. Psychoneuroimmunology: Psychological influences on immune function and health. J Consult Clin Psychol 70(2):537-47

Krantz DS, McCeney MK. 2002. Effects of psychological and social factors on organic disease: A critical assessment of research on coronary heart disease. Annu Rev Psychol 53(3):41-69.

Lazarus RS, Folkman S. 1984. Stress, Appraisal and Coping. New York, NY: Springer. 456 p.

Marmot MG, Smith GD, Stansfeld S, et al. 1991. Health inequalities among British civil servants: The Whitehall II Study. Lancet 337:1387-93.
[NCHS] National Center for Health Statistics. 2006. Health, United States, 2006: with Chartbook on Trends in the Health of Americans. Table 27. Life expectancy at birth, at 65 years of age, and at 75 years of age, by race and sex: United States, selected years 1900-2004. Hyattsville, MD. www.cdc.gov/nchs/data/ hus/hus06.pdf\#027 (accessed 2/27/06).

Park CL, Fenster JR. 2004. Stress-related growth: Predictors of occurrence and correlates with psychological adjustment. J Soc Clin Psychol 23(2):195-215.

Rabkin J, Streuning E. 1976. Life events, stress and illness. Science 194:1013-20.

Rowe JW, Kahn RL. 1998. Successful Aging. New York, NY: Pantheon. 288 p.

Schnurr P, Spiro A III, Aldwin CM, Stukel TA. 1998 Symptom trajectories following trauma exposure: Longitudinal findings from the Normative Aging Study. J Nerv Ment Disorder 186:522-8.

Shiraishi RW, Aldwin CM. 2002. Stress and coping across domains in early adulthood and midlife. Paper presented at Annual Meetings of the American Psychological Association, Chicago, IL.

Springborn RR. 2006. Abridged Life Tables for California, 2004. California Department of Health Services, Center for Health Statistics. Data Summary No DS0611002. www.cdph.ca.gov/pubsforms/Pubs/OHIRLife tables2004.pdf (accessed 2/27/06)

Stanton AL, Bower JE, Low CA. 2006. Post-traumatic growth after cancer. In Calhoun LG, Tedeschi R (eds.). Handbook of Post-traumatic Growth: Research and Practice. Mahwah, NJ: Lawrence Erlbaum. p 138-75.

Tedeschi RG, Calhoun LG. 2004. Post-traumatic growth: Conceptual foundations and empirical evidence. Psych Inquiry 15(1):1-18.

Yancura LA, Aldwin CM, Spiro A III. 1999. Does stress decrease with age? A longitudinal examination of stress in the Normative Aging Study. Gerontologist (abs.) 39:212 